\title{
Long-Distance Spore Transport of Wheat Stripe Rust Pathogen from Sichuan, Yunnan, and Guizhou in Southwestern China
}

\author{
Haiguang Wang, Department of Plant Pathology, China Agricultural University, Beijing 100193; X. B. Yang, De- \\ partment of Plant Pathology, Iowa State University, Ames 50011; and Zhanhong Ma, Department of Plant Pathol- \\ ogy, China Agricultural University, Beijing
}

\begin{abstract}
Wang, H., Yang, X. B., and Ma, Z. 2010. Long-distance spore transport of wheat stripe rust pathogen from Sichuan, Yunnan, and Guizhou in southwestern China. Plant Dis. 94:873-880.

Wheat stripe rust, caused by Puccinia striiformis f. sp. tritici, is the most devastating wheat disease in China. Although pathogens oversummering and overwintering in many regions of southwestern China have been studied, spore exchange among these regions is largely unknown. It is especially important to study the role of Sichuan, Yunnan, and Guizhou provinces in southwestern China in contributing to regional disease outbreaks in the major wheat-growing areas of China. Long-distance transport of $P$. striiformis $\mathrm{f}$. sp. tritici urediniospores after oversummering and overwintering in Sichuan, Yunnan, and Guizhou was investigated using the HYSPLIT-4 model based on meteorological data. Results suggest that the pathogen spores can interchange frequently among Sichuan, Yunnan, and Guizhou in both spring and autumn. The sources of inoculum in Sichuan, Yunnan, and Guizhou have a high probability of impacting the epidemics in northern, northwestern, and southwestern China. In particular, disease epidemics in Guizhou can be affected not only by local inoculum but also by that from Yunnan in the spring.
\end{abstract}

Wheat stripe rust, caused by Puccinia striiformis f. sp. tritici Erikss., is one of the most devastating wheat diseases in the world (12). In China, wheat stripe rust occurs in almost all wheat-growing regions. This disease is always a potential threat to wheat production in northwestern, northern, and southwestern China and in the middle and lower reaches of the Yangtze River. The four most destructive epidemics of wheat stripe rust in China occurred in 1950, 1964, 1990, and 2002, causing yield losses as high as 6.0, 3.2, 1.8 , and 1.3 million tons, respectively $(12,18-20)$.

Wheat stripe rust is a wind-dispersed pandemic disease (27). In most wheatproducing regions in China, $P$. striiformis f. sp. tritici usually oversummers or overwinters in different areas with different geographic climatic conditions, and then completes its life cycle by long-distance dispersal of urediniospores. In China, "Xuns" are equivalent to 10-day periods as follows: the early Xun is the first 10 days of a month, the mid Xun is the middle 10 days of a month, and the late Xun is the remaining days of a month. Even if suitable host plants exist, the pathogen cannot oversummer if the Xun's mean of daily

Corresponding author: H. Wang

E-mail: hgwangcau@gmail.com

Accepted for publication 15 February 2010.

doi:10.1094/PDIS-94-7-0873

(C) 2010 The American Phytopathological Society average temperatures in summer is above $22^{\circ} \mathrm{C}$. The oversummering areas of wheat stripe rust in China cover five regions, including northwestern China, northwestern Sichuan, Yunnan, northern China, and Xinjiang. Among these regions, northwestern China and northwestern Sichuan are the main inoculum source regions that can cause infection in autumn wheat seedlings in eastern China (12). A GIS-based regional classification of pathogen oversummering in China by Ma et al. (14) showed that the regions suitable for pathogen oversummering in Gansu, Sichuan, Yunnan, and Shaanxi are geographically adjacent to one another, and the regions in Guizhou are likely conjunct with those in Yunnan. These areas serve as an integrative region for pathogen oversummering. When the monthly mean of daily lowest temperatures drops to below $-6^{\circ} \mathrm{C}$, the pathogen can no longer overwinter (12). However, if the infected seedlings are covered by snow, the pathogen can still overwinter, even if the temperature is as low as $-10^{\circ} \mathrm{C}$. The overwintering borderline of this pathogen follows along Huangling in Shaanxi Province, Jiexiu in Shanxi Province, Shijiazhang in Hebei Province, and on to Dezhou in Shandong Province (12). North of the borderline, it is most unlikely that the pathogen can overwinter there.

Three epidemiological regions have been classified for the pandemic system in China. The regions are northern Chinanorthwestern China-the middle and lower reaches of the Yangtze River; Xinjiang; and Yunnan (12). The first region covers about $80 \%$ of wheat-growing areas in
China. It is thought that Xinjiang is isolated from the other two regions by mountains and deserts, and there is no clear evidence of inoculum exchange among these regions. Wheat stripe rust can oversummer in the mountainous areas where temperatures are cooler and more favorable for the pathogen and at the areas with high elevation in the middle, the west, and the northwest of Yunnan Province. The pathogen can also overwinter in Yunnan Province (11). It is not clear whether there is inoculum exchange between this region and northern China-northwestern Chinathe middle and lower reaches of the Yangtze River epidemiological region.

Sichuan, Yunnan, and Guizhou are topographically complex provinces located in southwestern China. Northwestern Sichuan and Yunnan were formerly considered to be separate oversummering regions, whereas pathogen oversummering in Guizhou has not yet been characterized. Sichuan Basin is an important winter propagation area of wheat stripe rust but the pathogen cannot oversummer in this basin. Northwestern Sichuan is the main pathogen oversummering area in this province, mainly including Aba, Ganzi, and Liangshan (12). The pathogen can oversummer in central, western, and northwestern Yunnan $(12,25)$. The pathogen oversummering region in Yunnan is the south edge, stretching from the northwestern China oversummering region through the south of the Longnan oversummering region in Gansu Province and the Sichuan oversummering region (25). Until recent years, pathogen oversummering in Guizhou Province was not investigated (22). In 2006, experts organized by the Agricultural Technology Extension and Service Center, Ministry of Agriculture of the People's Republic of China, surveyed and investigated the possibility of pathogen oversummering in Guizhou. They confirmed that the pathogen could oversummer in the areas above an elevation of $1,700 \mathrm{~m}$ in northwest Guizhou (22).

Aerial dispersal of plant pathogens can be considered as a sequence of events including spore liberation from infected plant tissues, transport via air currents, and deposition on the host canopy or plants $(4,30)$. For long-distance aerial dispersal, plant pathogens form spore clouds and then are transported by atmospheric circulation. Air parcel trajectory analysis has 
been used to establish links between source regions of long-distance aerial pathogen transport and target regions $(1,5)$. Trajectory analysis is a commonly used method to study aerial transport of pathogens. The HYSPLIT-4 (Hybrid SingleParticle Lagrangian Integrated Trajectory) model developed by NOAA Air Resources Laboratory and Australia's Bureau of Meteorology is a complete system for com- puting trajectory dispersion and deposition simulations using either a puff or a particle approach, by which forward trajectories and backward trajectories can be obtained (6). For example, Pan et al. (15) obtained trajectory frequencies at a $10-\mathrm{m}$ height for a 40-day period commencing on 7 August 2004 using a combination of the HYSPLIT-4 model with the mesoscale model (MM5) and predicted that spores of
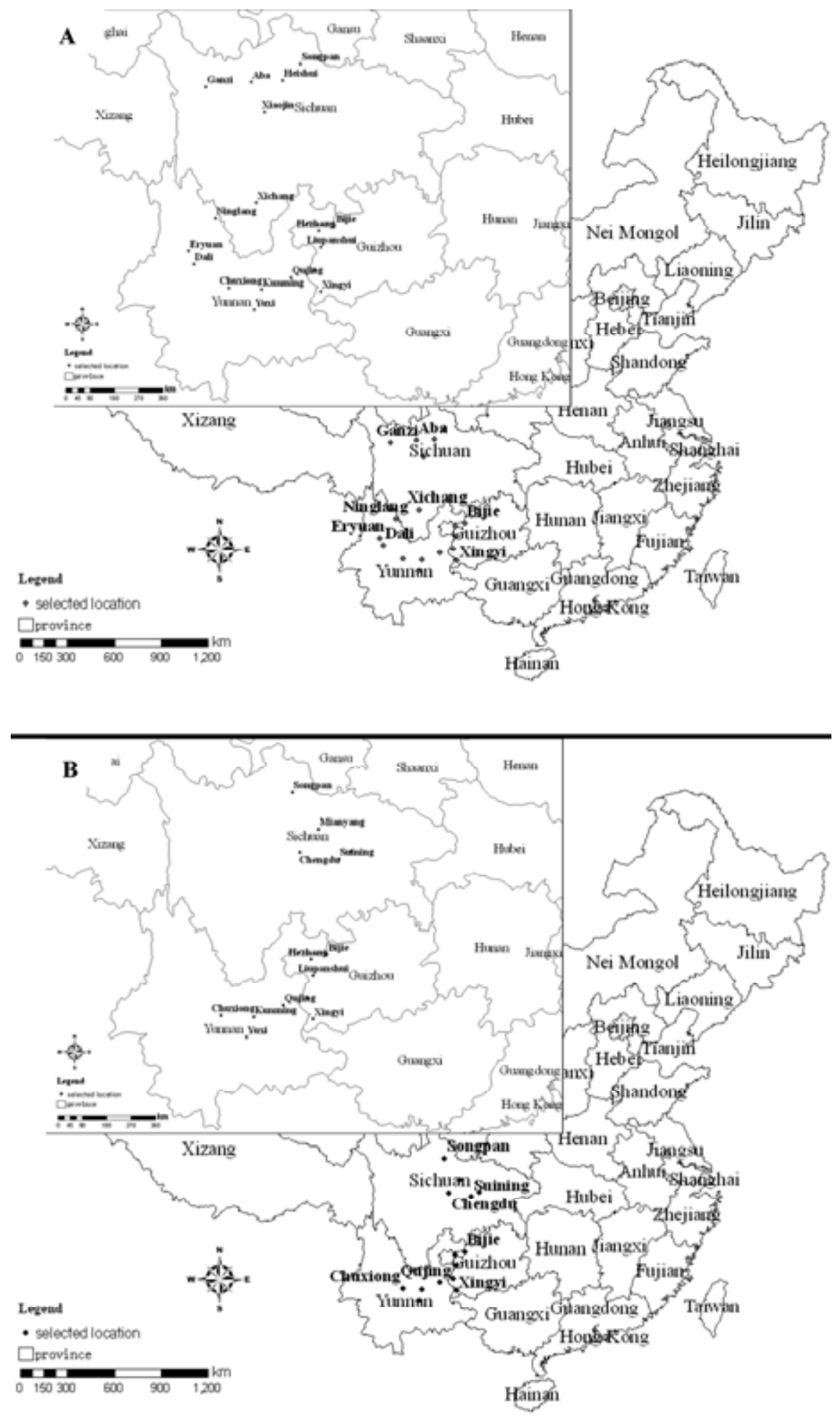

Fig. 1. Source locations selected from the A, oversummering and $\mathbf{B}$, overwintering regions of Puccinia striiformis f. sp. tritici in Sichuan, Yunnan, and Guizhou in China.

Phakopsora pachyrhizi, the soybean rust pathogen, originating from Colombia would be airborne northward to the southeastern United States and, as such, were able to predict arrival of the pathogen via long-distance transport of spores in Louisiana, which was confirmed laterally.

Regional-scale epidemics of wheat stripe rust in China are related to longdistance transport of the pathogen, and air current is the main driving force of transport $(10,12,24)$. Previous research (23) using the HYSPLIT-4 model has successfully shown that this model could be used to quantify long-distance transport of $P$. striiformis f. sp. tritici in China based on historical data. Therefore, the HYSPLIT-4 model was used in this study to investigate long-distance spore transport of Puccinia striiformis f. sp. tritici, with particular focus on the interrelationships between the inoculum sources in Sichuan, Yunnan, and Guizhou.

\section{MATERIALS AND METHODS}

Data collection. Source locations were defined as the locations where the pathogen could oversummer or overwinter and provide inoculum for initiating epidemics and were selected from the oversummering and overwintering regions as described by $\mathrm{Li}$ and Zeng (12). There was no firm evidence of the pathogen oversummering and overwintering in Guizhou Province; hence, Guizhou was considered to be an independent oversummering and overwintering region in this study. Five representative source locations, including Hezhang, Bijie, Liupanshui, Panxian, and Xingyi, where the pathogen could oversummer and overwinter, were selected in Guizhou according to the surveys by the Plant Protection and Quarantine Station of Guizhou Province. In total, 18 source locations from the pathogen oversummering regions in $\mathrm{Si}$ chuan, Yunnan, and Guizhou were selected (Fig. 1A), and another 14 source locations were selected as representatives of pathogen transport in spring from the overwintering regions (Fig. 1B).

Monthly meteorological data (i.e., FNL data) were obtained from the National Climatic Data Center using the HYSPLIT4 model for the period 1997 to 2006. Data were converted from a $1^{\circ}$ latitudelongitude grid to hemispheric 129 by 129 polar stereographic grids using NOAA's Air Resources Laboratory archiving program. They were outputted four times a day (i.e., at 00, 06, 12, and 18 UTC). The data contain variables such as the $\mathrm{u}$ - and $\mathrm{v}$ wind components, temperature, and humidity.

Modeling the transports of $P$. striiformis f. sp. tritici. As described by Draxler and Hess (6), the HYSPLIT-4 model uses a hybrid Eulerian-Lagrangian approach to calculate the trajectories and concentrations of particles in the air and on the ground. In this study, the inputs of the 
model were the coordinates of the spore sources and the FNL data. The outputs were trajectory frequencies and the plots were based on the trajectory frequencies.

Based on the FNL data, the trajectory frequencies on the grids were calculated for pathogen transport from each inoculum source location at 10 and $1,000 \mathrm{~m}$ above ground level (AGL) yearly from 1997 to 2006 using the HYSPLIT-4 model; then, the average trajectory frequency (ATF) over a period of 10 years for each selected target location at both elevations was cal- culated. The trajectory frequency plots for autumn pathogen transport in the period of 10 years from each inoculum source location at both elevations were also obtained. In order to explore the differences of pathogen transport from each province for each autumn, the corresponding trajectory frequency plots of pathogen transport from Sichuan, Yunnan, and Guizhou at 10 and 1,000 m AGL were obtained. The vertical motion calculation used the meteorological model's vertical velocity fields. Trajectory frequency was calculated as the number of trajectory intersections over each grid point divided by the total number of trajectories. In this study, the trajectory frequency on the grid that covered the potential target location was referred to as the trajectory frequency of the potential target location. A higher trajectory frequency in one location indicated an increased probability of deposition of spore from another location.

The starting date of inoculum source transport after oversummering was determined by the autumn wheat seeding date

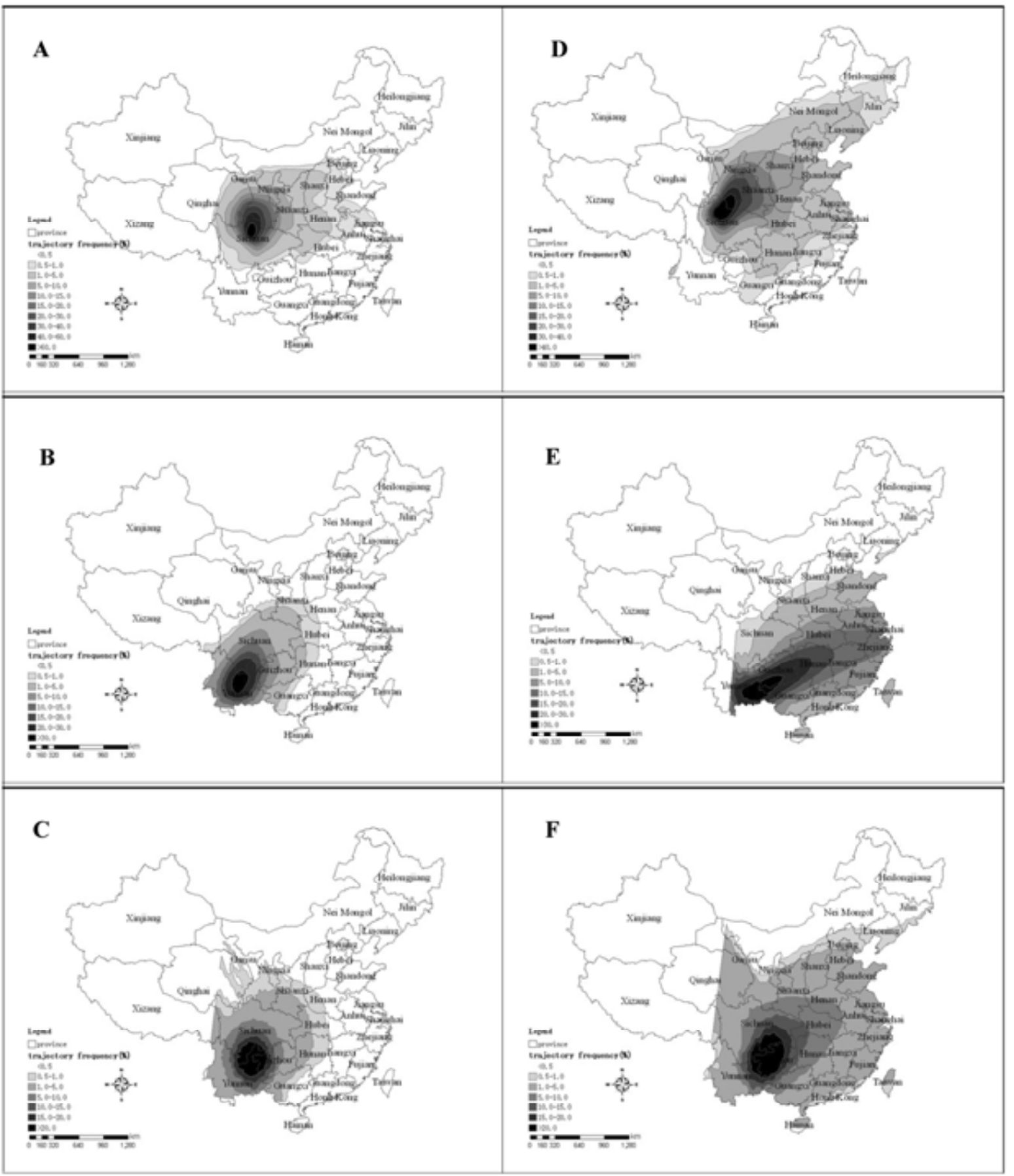

Fig. 2. Trajectory frequency plots of spore transport of Puccinia striiformis f. sp. tritici from locations in autumn (average from 1997 to 2006 ). High frequency represents high probability of dispersed pathogen from source to target. A, B, and C, Transport from Songpan in Sichuan, Yuxi in Yunnan, and Liupanshui in Guizhou, respectively, at $10 \mathrm{~m}$ above ground level (AGL). D, E, and F, Transport from Songpan in Sichuan, Yuxi in Yunnan, and Liupanshui in Guizhou, respectively, at 1,000 m AGL. 
and the onset date of the seedling disease of stripe rust. The starting date of inoculum source transport after overwintering was determined by the stages of wheat growth and the onset date of the seedling disease after revival. For each year, the model's running period for the selected source locations in Sichuan, Yunnan, and Guizhou was from 1 October to $10 \mathrm{No}$ vember. In every spring, the model's running period for the selected source locations was from 20 February to 10 April (Sichuan), 20 February to 31 March (Yunnan), and 1 March to 20 April (Guizhou). In each simulation, the pathogen spores were released four times a day (i.e., at 00, 06, 12, and 18 UTC). In this study, the spores were thought to be able to remain viable in the air for $120 \mathrm{~h}$; therefore, the total run time for each simulation was $120 \mathrm{~h}$.

\section{RESULTS}

Long-distance spore transport in autumn. Pathogen sources in the Sichuan oversummering region had high probability of transport into southern and eastern Gansu Province and southwestern Shaanxi Province (Fig. 2A and D). Central and southern Henan Province and northern Hubei Province had low probability (most
ATFs were 5 to $10 \%$ ) of receiving spores from the Sichuan oversummering region at $1,000 \mathrm{~m}$ AGL. Moreover, the ATF in Ninglang, Yunnan Province, from Xichang at $10 \mathrm{~m}$ AGL was $8.0 \%$; and the ATF in Hezhang, Guizhou Province, from Xichang at $1,000 \mathrm{~m}$ AGL was $9.8 \%$. The probability of pathogen transport into other regions outside Sichuan was very low (ATFs were $<5 \%$ ).

The probability of spore transport to Guizhou from source areas in the Yunnan oversummering region was high (Fig. 2B and E). The sources in Yunnan at $10 \mathrm{~m}$ AGL had very strong probability of transport into parts of Sichuan (ATFs in Xichang were all between 24.0 and $50.0 \%$, ATFs in Xiaojin were 7.2 to $33.0 \%$, and the ATF from Eryuan into Aba was 8.1\%.). The pathogen sources in Yunnan at 1,000 $\mathrm{m}$ AGL also had potential to be transported into southwestern Shaanxi Province, northern Hubei Province, and central and southern Henan Province (most ATFs were 5 to $10 \%$ ). Moreover, the sources at 1,000 $\mathrm{m}$ AGL had potential for impact in southwestern Sichuan.

After aerial dispersal of the pathogen from sources in the Guizhou oversummering region at $10 \mathrm{~m}$ AGL (Fig. 2C), ATFs were relatively high in Kunming and Yuxi in Yunnan and Xichang and Xiaojin in Sichuan (most ATFs were $>5 \%$; especially for Xichang, some ATFs were $>20 \%$ ). The pathogen in the Guizhou oversummering region at 1,000 $\mathrm{m}$ AGL might be one of the sources causing wheat stripe rust epidemics in southwestern Shaanxi Province, northern Hubei Province, and central and southern Henan Province (most ATFs were 5 to $12 \%$; Fig. $2 \mathrm{~F}$ ).

During autumn, the average trajectory frequency distribution after aerial longdistance transport of the pathogen at 10 or 1,000 $\mathrm{m}$ AGL varied across years from 1997 to 2006 (Figs. 3, 4, and 5). The probabilities of autumn dispersal from Sichuan at $10 \mathrm{~m}$ AGL to the northwestern wheatgrowing area were relatively high, whereas probabilities for transport to northern China and the middle and lower reaches of the Yangtze River were mid-level, and those for transport to Yunnan and Guizhou were very low, except to Ninglang in Yunnan (Fig. 3A and B). For the same sources at $1,000 \mathrm{~m} \mathrm{AGL}$, the probabilities of pathogen transport to northwestern and northern China were relatively high, and there were lower probabilities of transport to the middle and lower reaches of the Yangtze River and to northwestern Sichuan and northwestern Guizhou (Fig. 3C and

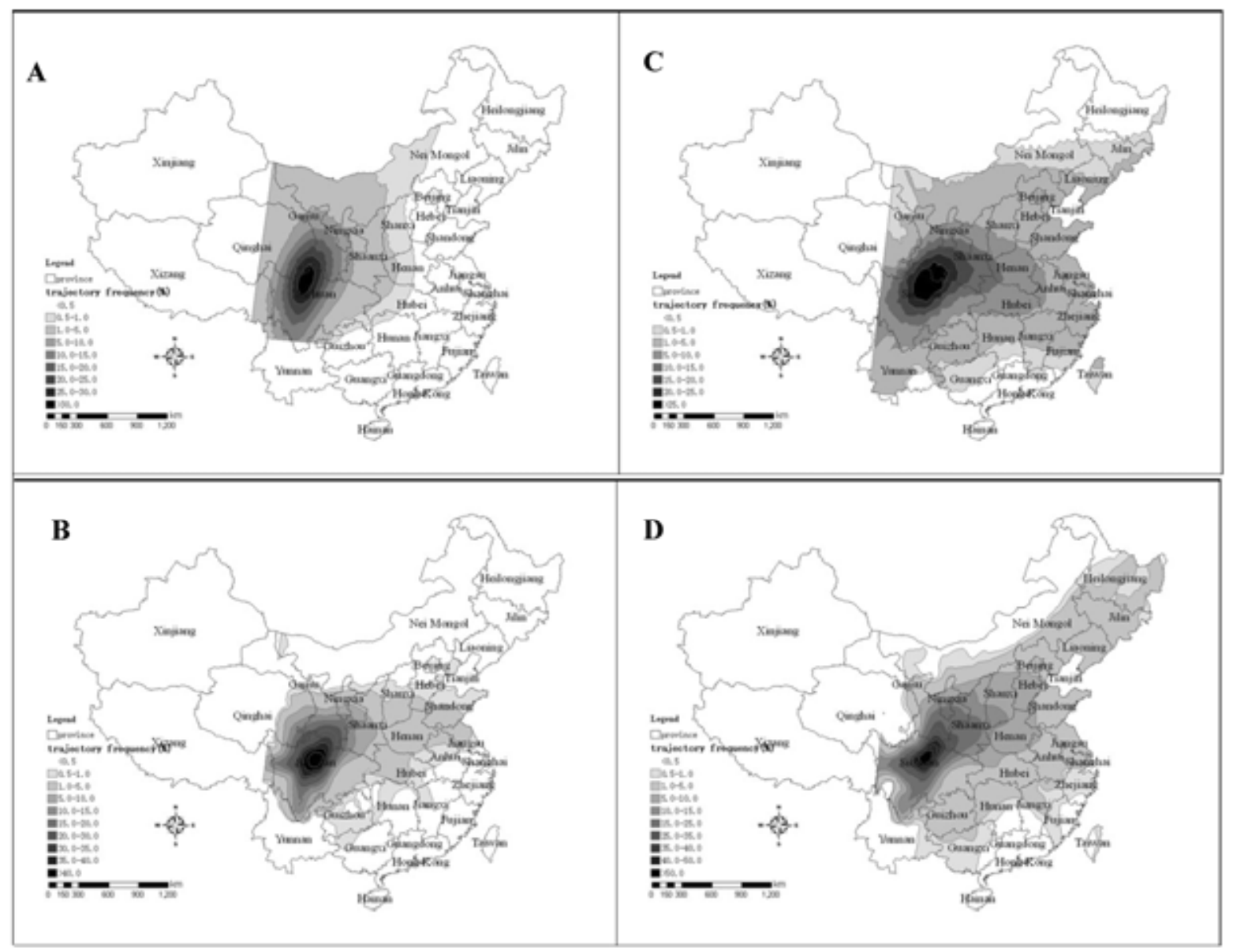

Fig. 3. Average trajectory frequency plots of spore transport of Puccinia striiformis f. sp. tritici from Sichuan Province in China in autumn. High frequency represents high probability of dispersed pathogen from source to target. A and B, Sources at $10 \mathrm{~m}$ above ground level (AGL) in 1997 and 2004, respectively. C and D, Sources at 1,000 m AGL in 1997 and 2004, respectively. 
D). The probabilities of transport of spores at $10 \mathrm{~m}$ AGL from Yunnan to Sichuan and Guizhou were at the highest levels in 2000, 2001, 2002, and 2006. The probabilities that the sources would be transported into western and northwestern Guizhou and Sichuan were high, whereas the probabilities were somewhat less for transport to northern and northwestern China and the middle and lower reaches of the Yangtze River (Fig. 4A and B). The pathogen sources at 1,000 $\mathrm{m}$ AGL from Yunnan were more frequently transported into Sichuan and Guizhou but there were also relatively high probabilities of transport into the middle and lower reaches of the Yangtze River, northwestern China, and central China (Fig. 4C and D). The sources in Guizhou at $10 \mathrm{~m}$ AGL had larger distribution coverage in 1997, 2000, and 2004 than in other years. The sources from Guizhou had high probabilities of transport to Yunnan and southeastern Sichuan and also had relatively high probabilities of transport into the middle and lower reaches of the Yangtze River, the south of Shaanxi Province, and the south of Henan Province (Fig. 5A and B). Similarly, the distribution coverage of the sources at $1,000 \mathrm{~m}$ AGL in Guizhou in autumn was larger than that at $10 \mathrm{~m}$ AGL. The sources at 1,000 m AGL had high probabilities of transport into the northeast of Yunnan, the south and the southeast of Sichuan, and the middle and lower reaches of the Yangtze River (Fig. 5C and D). They also had relatively high probabilities of transport to northwestern and northern China (Fig. 5C and D). The oversummering areas in northwestern Guizhou, northeastern and northwestern Yunnan, and southern and southeastern Sichuan were adjacent geographically, serving as an integrated oversummering area within which there were inoculum exchanges between the provinces and links to Longnan through northwestern Sichuan.

Long-distance spore transport in spring. The pathogen sources in the $\mathrm{Si}$ chuan overwintering region at $10 \mathrm{~m}$ AGL had the potential of being transported into Chongqing and into parts of Gansu, Shaanxi, Henan, Hebei, and Ningxia (Fig. $6 \mathrm{~A}$ ), whereas the probability that Yunnan would receive spores from Sichuan based on $10 \mathrm{~m}$ AGL was low. The pathogen sources in the Sichuan overwintering region at $1,000 \mathrm{~m}$ AGL had relatively high probabilities of transport into Chongqing, northwestern China, northern Hubei Province, and Henan (Fig. 6D). Moreover, parts of Guizhou (for example,
Zunyi) had lesser probabilities of receiving the spores from Sichuan at 1,000 m AGL.

After aerial dispersal of the pathogen sources in the Yunnan overwintering region at $10 \mathrm{~m}$ AGL (Fig. 6B), the probabilities of spore transport into Guizhou Province were high (ATFs were $>22 \%$ ), and relatively high for transport into Chongqing (ATFs were $>15 \%$ ). Additionally, at $10 \mathrm{~m} \mathrm{AGL}$, the pathogen had the potential to be transported into southwestern Sichuan and northern Hubei. The spores could be transported from the Yunnan overwintering region at 1,000 $\mathrm{m}$ AGL into Guizhou Province, Chongqing, northern Hubei, and southern Henan (most ATFs were $>5 \%$; Fig. $6 \mathrm{E}$ ).

After aerial dispersal of the pathogen in the Guizhou overwintering region at $10 \mathrm{~m}$ AGL (Fig. 6C), the ATFs for transport into Chongqing were about $20 \%$. The pathogen also could be transported into southwestern Sichuan, northern Hubei, and southwestern Shaanxi (ATFs were all above $5 \%$ ). At $1,000 \mathrm{~m}$ AGL, the pathogen sources in the Guizhou overwintering region could be transported into Chongqing, central and southern Shaanxi, northern Hubei, and central and southern Henan (most ATFs were $>5 \%$; Fig. 6F).

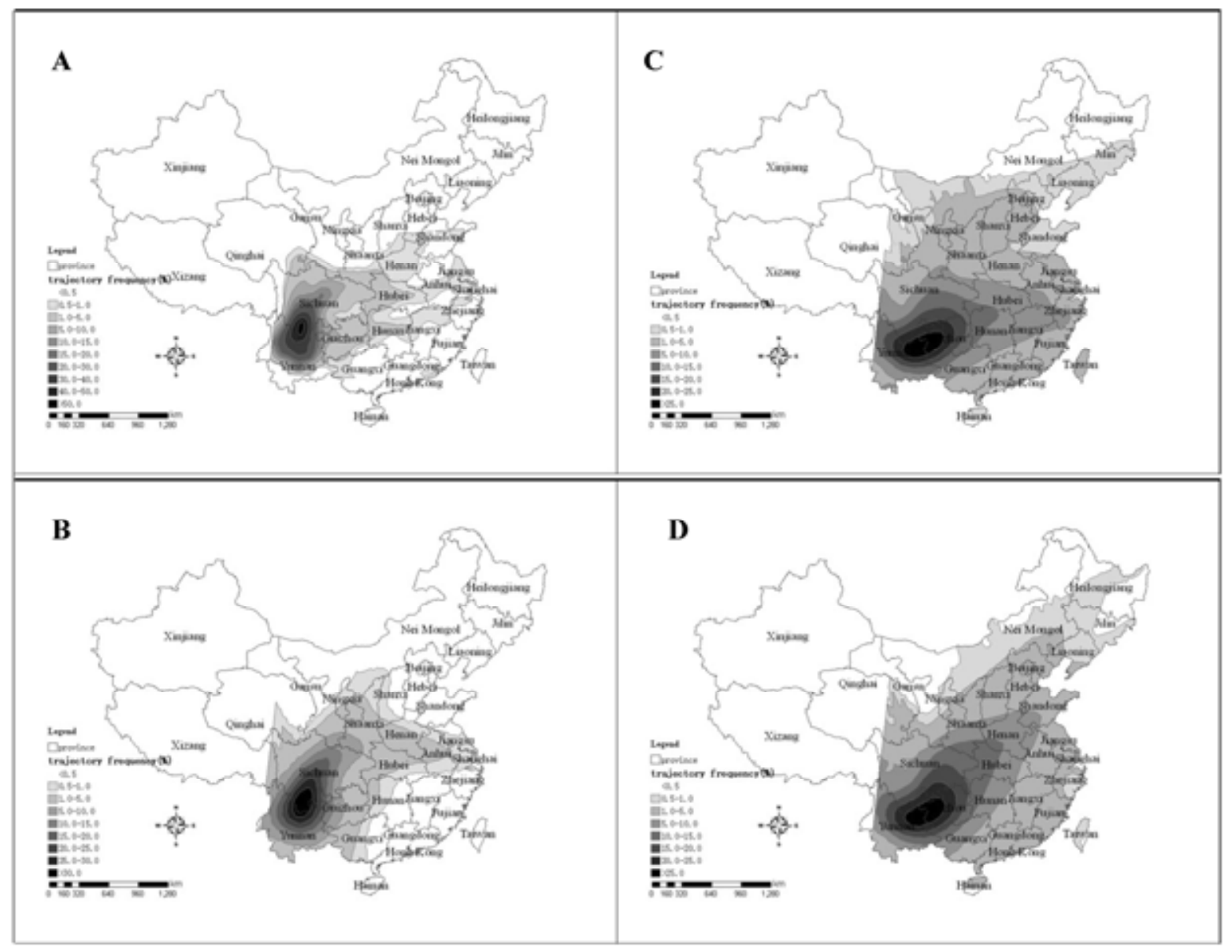

Fig. 4. Average trajectory frequency plots of spore transport of Puccinia striiformis f. sp. tritici from Yunnan Province in China in autumn. High frequency represents high probability of dispersed pathogen from source to target. A and B, Sources at $10 \mathrm{~m}$ above ground level (AGL) in 1997 and 2004, respectively. C and D, Sources at 1,000 m AGL in 1997 and 2004, respectively. 


\section{DISCUSSION}

Prior to our study, the importance of inoculum sources in southwestern China to the stripe rust pandemics in the north China wheat-production region was largely undetermined. There have been suggestions $(12,14)$ that inoculum in this region may contribute to national pandemics but they remained speculations because of lack of research tools. In this study, the longdistance spore transport of wheat stripe rust from Sichuan, Yunnan, and Guizhou after oversummering and overwintering were studied using the HYSPLIT-4 model. Our modeling results suggest that there is a high probability of significant spore exchanges among wheat-production regions in these three provinces in autumn. There seem to be connections through spore exchanges among Guizhou, Yunnan, and Sichuan with the winter wheat-production areas, and the three regions make up a unique source area. This source area has a high probability of providing spores to southern Gansu through northwestern Sichuan. This integrated oversummering region could have an impact on the occurrence of wheat stripe rust in the autumn wheat seedlings in the middle and lower reaches of the Yangtze River, northwestern China, and central China.
Ours results are similar to those of Yang and Ran (25) about the role of the Yunnan oversummering region and are also consistent with the results by $\mathrm{Ma}$ et al. (14) that the region in Guizhou suitable for oversummering of the pathogen could be integrated with the Yunnan oversummering region. In spring, the sources of inoculum in Sichuan, Yunnan, and Guizhou could be transported into the wheat areas of northern, northwestern, and southwestern China. In addition to the local sources, Guizhou's wheat-growing areas could also receive the pathogen from Yunnan in spring. Also in spring, the sources from Guizhou would be transported mainly into Sichuan, Chongqing, the middle and lower reaches of the Yangtze River, and central China. In autumn, the inoculum from Guizhou would be transported mainly into the southwestern China wheat-growing area, the middle and lower reaches of the Yangtze River, central China, and Hanzhong and Baoji of Shaanxi Province in northwestern China. Therefore, the role of the sources in Guizhou could not be neglected. This study is a significant contribution to the understanding of the wheat stripe rust pandemic in China, especially the longdistance transport of the pathogen. It is also a significant advancement to largescale seasonal outbreak forecasting.

In addition to traditional field surveys, methods such as mathematical statistics models, simulation models, and molecular biological methods also have been used to study long-distance transport of wheat stripe rust $(3,7,10,17,24,26,28,29,31)$. The HYSPLIT-4 model used in this study is a mechanical model of air circulation. The liberation, transportation, and deposition of pathogen spores can be investigated with this model. This method can further reveal the mechanism of regional spore dispersion. Combined with other models, such as the MM5 and Weather Research Forecast, which can be used to obtain highresolution meteorological field data, the HYSPLIT-4 model can be used to obtain results with high precision. The successful example of soybean rust forecasting in the continental United States (15) could provide an approach to regional forecast of wheat strip rust in China.

The trajectory model can be combined with remote sensing (RS) techniques to determine the movement of wheat stripe rust. Prospero et al. (16) analyzed the characteristics of long-distance transport of bacteria and fungi from Africa using TOMS images and investigated the trajec-

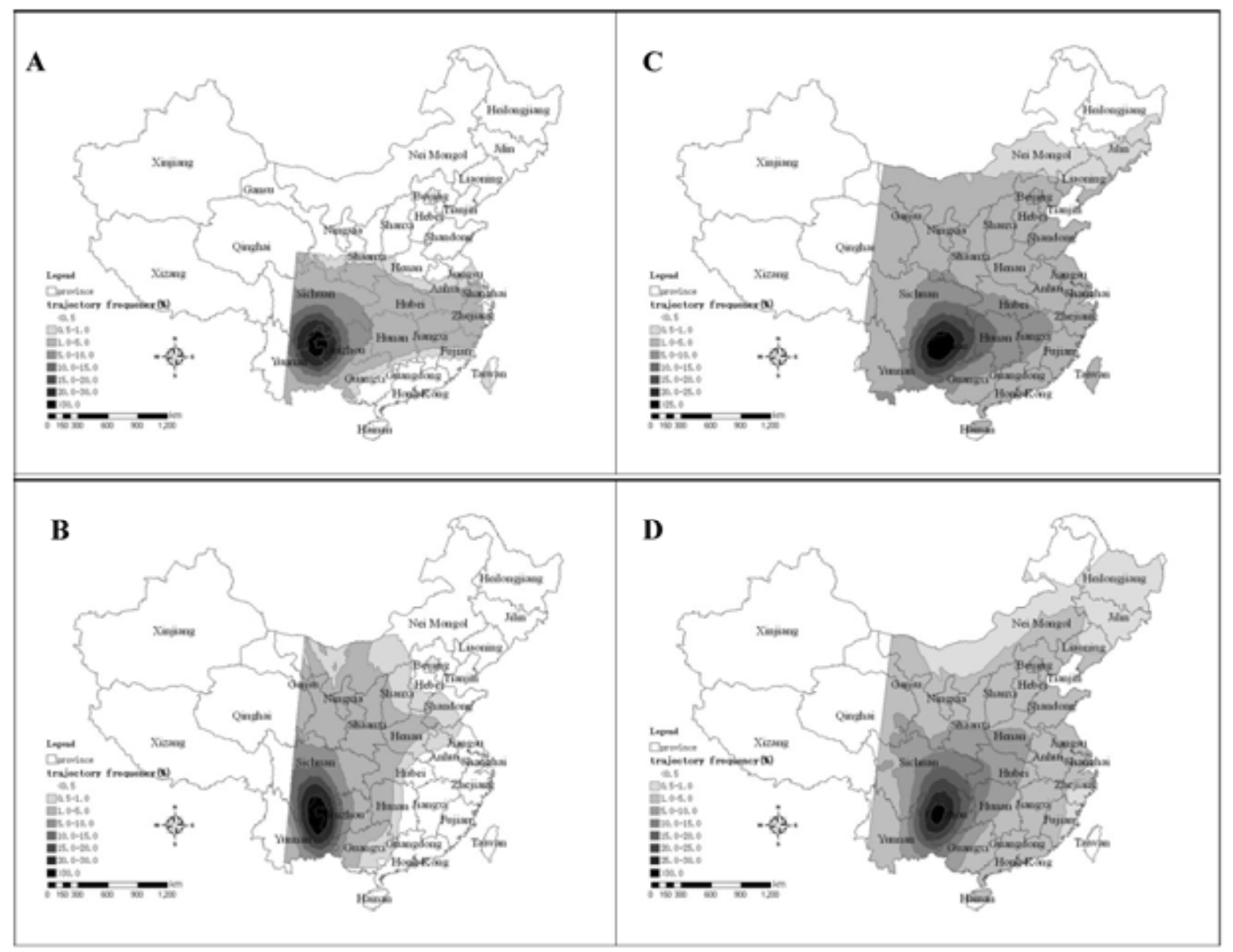

Fig. 5. Average trajectory frequency plots of spore transport of Puccinia striiformis f. sp. tritici from Guizhou Province in China in autumn. High frequency represents high probability of dispersed pathogen from source to target. A and B, Sources at $10 \mathrm{~m}$ above ground level (AGL) in 1997 and 2004, respectively. C and D, Sources at 1,000 m AGL in 1997 and 2004, respectively. 
tories of long-distance pathogen transport using the HYSPLIT-4 model. They realized that the combination of TOMS images and the HYSPLIT-4 model could provide strong support for understanding the longdistance transport of the pathogens. Because the studies on monitoring wheat stripe rust using RS have progressed very well in recent years $(2,8,9,13,21)$, the combination of techniques related to air circulation with RS techniques can be used to study the long-distance transport of wheat stripe rust and also to monitor and forecast the epidemics of the disease on a macro scale.

\section{ACKNOWLEDGMENTS}

We thank the NOAA Air Resources Laboratory for providing the HYSPLIT-4 transport and dispersion model and for permission to use the READY website (http://www.arl.noaa.gov/ready.html); Z. Pan at St. Louis University for suggestions; and Yong Luo, University of California-Davis, Kearney Agricultural Center, Parlier, CA, for providing critical review of the manuscript prior to submission.

\section{LITERATURE CITED}

1. Aylor, D. E. 1986. A framework for examining inter-regional aerial transport of fungal spores. Agric. For. Meteorol. 38:263-288.

2. Cai, C. J., Ma, Z. H., Wang, H. G., Zhang, Y. P., and Huang, W. J. 2007. Comparison research of hyperspectral properties between near-ground and high altitude of wheat stripe rust. Acta Phytopathol. Sin. 37:77-82.

3. Chen, G., Wang, H. G., Zhang, L. D., Wang, T., and Ma, Z. H. 2006. Preliminary research on the regional relationship of epidemic of Puccinia striiformis in China. Chin. Agric. Sci. Bull. 22:415-420.

4. Cooke, B. M., Gareth Jones, D., and Kaye, B. 2006. Pages 159-416 in: The Epidemiology of Plant Diseases, 2nd ed. Springer, Dordrecht, The Netherlands.

5. Davis, J. M. 1987. Modeling the long-range transport of plant pathogens in the atmosphere. Annu. Rev. Phytopathol. 25:169-188.

6. Draxler, R. R., and Hess, G. D. 1998. An overview of the Hysplit-4 modeling system for trajectories, dispersion, and deposition. Aust. Meteorol. Mag. 47:295-308.

7. Hovmøller, M. S., Justesen, A. F., and Brown,

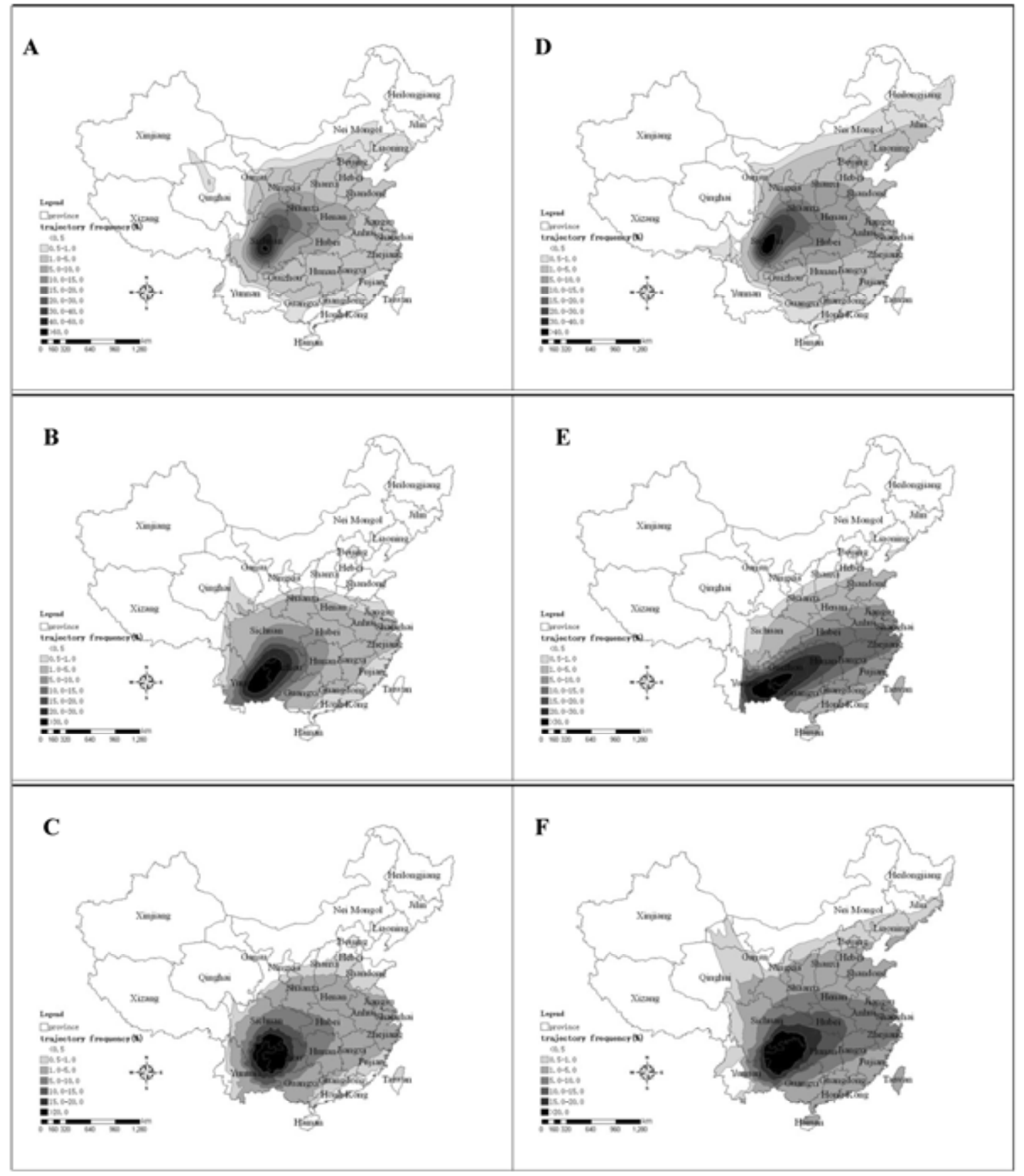

Fig. 6. Trajectory frequency plots of spore transport of oversummered Puccinia striiformis f. sp. tritici from locations in spring (average of 1997 to 2006). High frequency represents high probability of dispersed pathogen from source to target. A, B, and $\mathbf{C}$, Transport from Chengdu in Sichuan, Yuxi in Yunnan, and Liupanshui in Guizhou, respectively, at $10 \mathrm{~m}$ above ground level (AGL). D, E, and F, Transport from Chengdu in Sichuan, Yuxi in Yunnan, and Liupanshui in Guizhou, respectively, at 1,000 m AGL. 
J. K. M. 2002. Clonality and long-distance migration of Puccinia striiformis f. sp. tritici in north-west Europe. Plant Pathol. 51:24-32.

8. Huang, M. Y., Wang, J. H., Huang, W. J., Huang, Y. D., Zhao, C. J., and Wan A. M. 2003. Hyperspectral character of stripe rust winter wheat and monitoring by remote sensing. Trans. CSAE 19:154-158.

9. Huang, W. J., Huang, M. Y., Liu, L. Y., Wang, J. H., Zhao, C. J., and Wang, J. D. 2005. Inversion of the severity of winter wheat yellow rust using proper hyper spectral index. Trans. CSAE 21:97-103.

10. Jiang, Y., Huo, Z. G., Li, S. K., and Bai, Q. F. 2006. A comparative research on long-term forecasting models for countrywide wheat stripe rust. J. Nat. Disasters 15:109-113.

11. Li, M. J. 2004. Current research situation on epidemic system of wheat stripe rust in Yunnan Province. Plant Prot. 30:30-33.

12. Li, Z. Q., and Zeng, S. M. 2002. Pages 1-254 in: Wheat Rusts in China. China Agriculture Press, Beijing.

13. Liu, L. Y., Huang, M. Y., Huang, W. J., Wang, J. H., Zhao, C. J., Zheng, L. F., and Tong, Q. X. 2004. Monitoring stripe rust disease of winter wheat using multi-temporal hyperspectral airborne data. J. Remote Sens. 8:275-281.

14. Ma, Z. H., Shi, S. D., Jiang, Y. Y., and Zhao, Z. H. 2005. Climate-based regional classification for oversummering of Puccinia striiformis in China with GIS. Acta Phytopathol. Sin. 34:455-462.

15. Pan, Z., Yang, X. B., Pivonia, S., Xue, L.,
Pasken, R., and Roads, J. 2006. Long-term prediction of soybean rust entry into the continental United States. Plant Dis. 90:840-846.

16. Prospero, J. M., Blades, E., Mathison, G., and Naidu, R. 2005. Interhemispheric transport of viable fungi and bacteria from Africa to the Caribbean with soil dust. Aerobiologia 21:119.

17. Shan, W. X., Chen, S. Y., Wu, L. R., and Li, Z. Q. 1995. RAPD analysis of epidemic races of Puccinia striiformis f. sp. tritici in China. Sci. Agric. Sin. 28:1-7.

18. Wan, A., Zhao, Z., Chen, X., He, Z., Jin, S., Jia, Q., Yao, G., Yang, J., Wang, B., Li, G., Bi, Y., and Yuan, Z. 2004. Wheat stripe rust epidemic and virulence of Puccinia striiformis $\mathrm{f}$. sp. tritici in China in 2002. Plant Dis. 88:896904.

19. Wan, A. M., Chen, X. M., and He, Z. H. 2007. Wheat stripe rust in China. Aust. J. Agric. Res. 58:605-619.

20. Wan, A. M., Zhao, Z. H., and Wu, L. R. 2003. Reviews of occurrence of wheat stripe rust disease in 2002 in China. Plant Prot. 29:5-8.

21. Wang, H. G., Ma, Z. H., Wang, T., Cai, C. J., An, H., and Zhang, L. D. 2007. Application of hyperspectral data to the classification and identification of severity of wheat stripe rust. Spectrosc. Spect. Anal. 27:1811-1814.

22. Wang, H. G., Tan, X. F., Jin, X., Feng, M. Y., and Ma, Z. H. 2007. Investigation on wheat stripe rust in autumn 2006 in Hezhang County of Guizhou Province. Chin. Agric. Sci. Bull. 23:360-364.
23. Wang, H. G., Yang, X. B., and Ma, Z. H. 2009. Case analysis of long-distance transports of Puccinia striiformis f. sp. tritici in China using HYSPLIT-4 model. Acta Phytopathol. Sin. 39:183-193.

24. Xie, S. X., Wang, K. N., Chen, Y. L., and Chen, W. Q. 1993. Preliminary studies on the relationship between transport of wheat stripe rust and the upper air current in China. Acta Phytopathol. Sin. 23:203-209.

25. Yang, S. C., and Ran, Y. 1986. Studies on the oversummering of Puccinia striiformis (West.) in Yunnan Province. Sci. Agric. Sin. 19:72-77.

26. Yun, X. W., Wang, H. G., and Ma, Z. H. 2007. Forecast of wheat stripe rust by upper-air wind. Chin. Agric. Sci. Bull. 23:358-363.

27. Zeng, S. M. 1963. On the epidemiological region system of wheat yellow rust in China. Plant Prot. 1:10-13.

28. Zeng, S. M. 1988. Interregional spread of wheat yellow rust in China. Acta Phytopathol. Sin. 18:219-223.

29. Zeng, S. M. 1991. PANCRIN, a prototype model of the pandemic cultivar-race interaction of yellow rust on wheat in China. Plant Pathol. 40:287-295.

30. Zeng, S. M., and Yang, Y. 1988. Pages 118-150 in: Plant Disease Epidemiology. Agriculture Press, Beijing.

31. Zeng, S. M., and Zhang, M. R. 1990. Simulation experiments on the pandemic dynamic of wheat stripe rust in China by means of a simulation model PANDCRIN. J. Beijing Agric. Univ. 16(Suppl.):151-162. 